\title{
Characterization of a Forebrain Gaze Field in the Archistriatum of the Barn Owl: Microstimulation and Anatomical Connections
}

\author{
Eric I. Knudsen, Yale E. Cohen, and Thomas Masino \\ Department of Neurobiology, Stanford University School of Medicine, Stanford, California 94305-5401
}

We present evidence that the archistriatum in the forebrain of the barn owl participates in gaze control, that it can mediate gaze changes independently of the optic tectum (OT), and that it projects in parallel to both the OT and to saccade-generating circuitry in the brainstem tegmentum. These properties are similar to those of the frontal eye fields (FEF) in the prefrontal cortex of primates.

The forebrain was surveyed for sites where electrical microstimulation would induce head saccades. Head (and eye) saccades were elicited from the anterior $70 \%$ of the archistriatum, a region that we refer to as the archistriatal gaze fields (AGF). At single stimulation sites in the AGF, saccade amplitude tended to vary as a function of stimulation parameters (current strength, pulse frequency, and train duration) and starting head position. In contrast, saccade direction was largely independent of these parameters. Saccade direction did vary over a wide range of primarily contraversive directions with the site of stimulation in the AGF.

Using anatomical pathway tracing techniques, we found that the archistriatum projects strongly and in parallel to the deep layers of the OT and to nuclei in the midline brainstem tegmentum. Previous work has shown that electrical microstimulation of either of these brainstem regions evokes saccadic movements of the head and/or eyes (du Lac and Knudsen, 1990; Masino and Knudsen, 1992b). Inactivation of the OT with lidocaine reduced the size but did not eliminate (or change the direction of) the saccades evoked by AGF stimulation. The direct anatomical pathway from the archistriatum to the midline tegmental nuclei can account for saccades that persist following OT inactivation.

The similarities between the AGF in barn owls and the FEF in primates suggest that the same general plan of anatomical and functional organization supports the contribution of the forebrain to gaze control in a wide variety of species.

[Key words: orienting movements, eye saccades, frontal eye fields, gaze control, superior colliculus, optic tectum]

Received Oct. 20, 1991; revised Feb. 28, 1995; accepted Mar. 3, 1995.

We thank Michael Brainard for reviewing the manuscript and Phyllis Knudsen for technical support. This work was supported by Grant R01 DC0015515 from the National Institutes of I Iealth.

Correspondence should be addressed to Eric Knudsen, Department of Neurobiology, Fairchild Building, Room D257, Stanford University School of Medicine, Stanford, CA 94305-5401.

Copyright (C) 1995 Society for Neuroscience $0270-6474 / 95 / 155139-13 \$ 05.00 / 0$
Barn owls shift their gaze primarily by turning the head, since eye movements are limited to just a few degrees (Knudsen, 1989). Although gaze shifts are carried out primarily by the head, the kinematics of the movements are strikingly similar to those of primate eye saccades (Robinson, 1972; Westheimer, 1973; du Lac and Knudsen, 1990). Moreover, head saccades in barn owls and eye saccades in primates are subserved by similar brainstem nuclei that transform premotor commands into Cartesian components (up, down, left, and right) of saccadic move ment (Henn et al., 1982; Fukushima, 1987; Masino and Knudsen, 1990, 1992b).

In mammals, both the frontal eye fields (FEF) in the prefrontal cortex and the superior colliculus in the midbrain contribute to the control of gaze (Bruce, 1990; Stein and Meredith, 1993). The FEF participate primarily in voluntary shifts of gaze whereas the superior colliculus participates in all types of saccadic orienting movements (Wurtz and Goldberg, 1972; Bruce and Goldberg, 1985; Goldberg and Segraves, 1989).

The gaze shifts initiated by the FEF are mediated, in part, by activation of the superior colliculus (Segraves and Goldberg, 1987). However, after ablation of the superior colliculus, monkeys still are capable of making saccadic gaze shifts and electrical stimulation of the FEF still elicits eye saccades (Schiller, 1977; Schiller et al., 1980). Similarly, after ablation of the FEF while leaving the superior colliculus intact, monkeys continue to make eye saccades. However, the capacity to make saccadic shifts of gaze is lost following the ablation of both structures. Thus, the FEF and the superior colliculus have independent access to the brainstem saccade generators, and together these regions of the brain are responsible for rapid orientations of gaze.

In nonmammalian species, the optic tectum (OT; homolog of the superior colliculus) has been regarded as the mediator of saccadic gaze shifts (Grobstein, 1988). However, recent experiments with barn owls have revealed that after removal of the OT, owls continue to make saccadic orienting movements to acoustic targets, and, after weeks of recovery, owls regain a limited capacity to make saccadic gaze shifts toward visual stimuli (Knudsen et al., 1993). The gaze shifts to acoustic targets that persist after tectal inactivation are abolished by blocking auditory input to the forebrain, suggesting that in barn owls, as in mammals, the forebrain and the midbrain have independent access to saccade-generating circuitry in the brainstem tegmentum.

The goal of the current experiments was to identify and char acterize a region of the owl's forebrain that can mediate saccadic orienting movements independently of the OT. We surveyed the forebrain using microstimulation in search of regions from 
which saccadic head turns could be evoked. We found that saccadic head turns were elicited consistently by microstimulation in the anterior portion of the archistriatum, a region that we will refer to as the archistriatal gaze fields (AGF). The archistriatum is thought to be functionally analogous to sensorimotor cortex in mammals (Zeier and Karten, 1971) and has been shown previously to be involved in high-level motor control (Zeier, 1971; Nottebohm et al., 1976; McCasland, 1987). Here we demonstrate that electrical microstimulation in the AGF elicits saccadic shifts of gaze, that these saccades persist following OT inactivation, and that the pattern of anatomical projections from the archistriatum to the regions of the saccade generators in the brainstem tegmentum and to the basal ganglia bear remarkable similarity to the descending pathways from the FEF that contribute to gaze control in mammals.

\section{Materials and Methods}

Eleven adult barn owls (Tyto alba) were used in these experiments. The effects of electrical microstimulation were studied in five owls; anatomical experiments were conducted in nine owls, three of which were also involved in the microstimulation experiments.

Preparation for microstimulation. Microstimulation of the forebrain was performed using a head-mounted microdrive capable of movement in three dimensions. The microdrive and the mounting procedure have been described in detail previously (Masino and Knudsen, 1992b). A dovetailed base for the microdrive was permanently attached over a craniotomy in the dorsal surface of the skull while the owl was anesthetized using halothane $(1 \%)$ and nitrous oxide $\left(\mathrm{O}_{2}: \mathrm{NO}_{2}=55: 45\right)$. The scalp was treated with betadine antiseptic agent, chloramphenicol solution was applied to the dura to prevent infection, the craniotomy was sealed with bone wax, and wound edges were infused with lidocaine. A bolt for securing the head to a stereotaxic device was mounted caudal to the microdrive base.

Stimulation experiments were conducted over periods of several weeks on each owl. For these experiments, the owl was anesthetized briefly using halothane and nitrous oxide, wrapped in a chamois cloth, and placed in a tube which allowed unrestricted head movements but no other body movements. The owl was centered in a room that contained electromagnetic induction coils. A search coil was attached to the top of the head in such a way that the plane of the coil was normal to the owl's visual axes. The craniotomy was opened, the opening was filled with chloramphenicol, and current return and ground leads were attached to the skin.

Stimulation electrodes consisted of electrolytically sharpened, epoxycoated tungsten rods with $12-15 \mu \mathrm{m}$ of exposed metal at the tip. Constant current, electrically isolated stimulus pulse trains were delivered from a Grass S88 stimulator and model PSIU6 isolation units. Biphasic stimulus pulses were $150 \mu \mathrm{sec}$ cathodal followed immediately by 150 $\mu \mathrm{sec}$ anodal currents at $200-400 \mathrm{~Hz}$ for $60-80 \mathrm{msec}$. Current strength ranged up to $600 \mu \mathrm{A}$ which, according to studies by Ranck (1980), would activate low threshold axons at a distance of up to about $1 \mathrm{~mm}$. Typically, the movements evoked from a single site decreased in amplitude with repetitive stimulation. In an attempt to elicit responses that were as consistent as possible, most sites were stimulated at long intervals, of 5-10 sec, and with current strengths not exceeding twice threshold (see below).

Most regions of the forebrain (hyperstriatum, neostriatum, paleostriatum, archistriatum, and ectostriatum) were included in an initial survey of areas eliciting head saccades. Since the greatest concentration of sites from which head saccades could be elicited were found in the archistriatum, the experiments in the last three owls focused on this brain region. During the scarch for movement areas, elcetrode penctrations were made at $1 \mathrm{~mm}$ intervals rostrocaudally and mediolaterally in a grid pattern. In most cases, the stimulation parameters used when searching for movement sites were as follows: current strength, $400 \mu \mathrm{A}$; train duration, $60 \mathrm{msec}$; pulse frequency, $300 \mathrm{~Hz}$. Upon encountering an area that produced rapid head turns reliably, that area was surveyed using $0.5 \mathrm{~mm}$ penetration intervals and lower current levels.

Movement characterization. Search coil output, representing the horizontal and vertical components of head movement, was digitized at 1 $\mathrm{kHz}$. Horizontal position was defined as position relative to the midsagittal plane of the body. Vertical position was defined as position relative to the horizontal plane that contained the visual axes when the head was centered on the body (Knudsen, 1982).

At each stimulation site that produced head movement, current strength was decreased and then was increased gradually until a movement was elicited in response to each stimulation. This current strength was defined as the threshold strength for that site. Two series of measurements were carried out using a current strength that was twice threshold. In the first series of measurements, the head of the alert owl was moved manually to a fixed position from which stimulation produced relatively large amplitude movements. Kinematic data are based on movements from this fixed starting position. In the second series of measurements, the owl was coaxed to turn its head to a wide range of starting positions with a combination of auditory, visual, and tactile stimuli. The analysis of the effects of starting head position on movement trajectory was based on these data.

Movement characteristics, including latency, velocity, duration, and direction were quantified for each trace using customized software. Representations of horizonlal and vertical velocities were generated by first smoothing the position trace using a centered running train average, weighted according to a Gaussian distribution that fell to half-maximum over $3 \mathrm{msec}$. Velocity was derived from differences between adjacent points in the smoothed position traces. Movement onset was the time and location at which head speed exceeded 1.5 times the maximum speed in the 15 msec prior to stimulation (baseline speed). Movement endpoint was the time and position at which speed returned to within 1.5 times the baseline speed. Latency was the time between stimulation onset and movement onset. Maximum velocity $\left(V_{\max }\right)$ was the highest speed attained during a movement. Direction was the arctangent of the difference between the onset and endpoint positions; directions were defined in a polar coordinate system in which $0^{\circ}$ indicated a vertical upward movement, $90^{\circ}$ a purely contraversive movement, $-90^{\circ}$ an ipsiversive movement, and $180^{\circ}$ or $-180^{\circ}$ a downward movement.

Definition of a saccadic head turn. Natural head saccades by barn owls are rapid turns of the head that have symmetric velocity profiles and end with the head maintained in a new position. The kinematics of these movements and the relationship between $V_{\max }$ and movement amplitude have been described previously (du Lac and Knudsen, 1990). For natural head saccades, $V_{\max }$ exceeds $40 \% \mathrm{sec}$ for movement amplitudes of up to $5^{\circ}$, and increases at a rate of about $13^{\circ} / \mathrm{sec}$ per degree of head rotation for larger saccades. Head movements measured in this study were defined as "saccades" if they exhibited velocity profiles and $V_{\max }$ values that were commensurate with these properties.

Tectal inactivation. The contribution of the OT to saccades produced by stimulating the AGF was assessed in two owls by inactivating the OT. In these owls, two stimulating electrodes were cemented in place in the ipsilateral tectal lobe, one at the rostral pole and the other near the caudal pole of the tectum. Tectally mediated, saccadic head movements could be evoked by passing pulse trains of current betwecn these electrodes. A stainless steel guide tube (21 gauge) was implanted so that an injector tube ( 25 gauge), when seated in the guide tube, was positioned in the center of the tectum (visual receptive field: $25^{\circ}$ contralateral, $0^{\circ}$ elevation; Knudsen, 1982). To inactivate the OT, lidocaine (2\%) was injected into the OT through the injector tube. Details of the techniques for positioning the guide tube and injecting drugs have been published previously (Knudsen et al., 1993).

Several movements were evoked from an AGF site prior to reversible OT inactivation. While the AGF stimulating electrode remained in place, the tectum was injected with lidocaine $(2-4 \mu \mathrm{l})$ until direct tectal stimulation no longer produced rapid head movements (within $5 \mathrm{~min}$ of injection). The movements produced by AGF and OT stimulation were then assayed over the next $15 \mathrm{~min}$. After $45 \mathrm{~min}$, the effects of the lidocaine on tectally elicited saccades had disappeared, and saccades elicited by AGF stimulation were measured again.

Reconstruction of stimulation sites. Electrolytic lesions $(20 \mu \mathrm{A}, 20$ $\mathrm{sec}$, electrode negative) were placed at or near the centers of regions from which head saccades were evoked. The locations of effective stimulation sites were reconstructed in Nissl-stained sections using these lesions to calibrate the stereotaxic coordinates of the head-mounted microdrive.

Anatomical experiments. Biotinylated dextran-amine (BDA; $0.2 \mu \mathrm{g}$ in $0.2 \mu \mathrm{l}$ of $0.2 \mathrm{M} \mathrm{KCl}$ and $3 \%$ Triton $\mathrm{X}$ ) and/or rhodamine labeled latex beads were injected at various sites in nine owls. Injections into the archistriatum were made in four owls; in one of these owls, the paleostriatum augmentatum (PA) on the opposite side was also injected. 

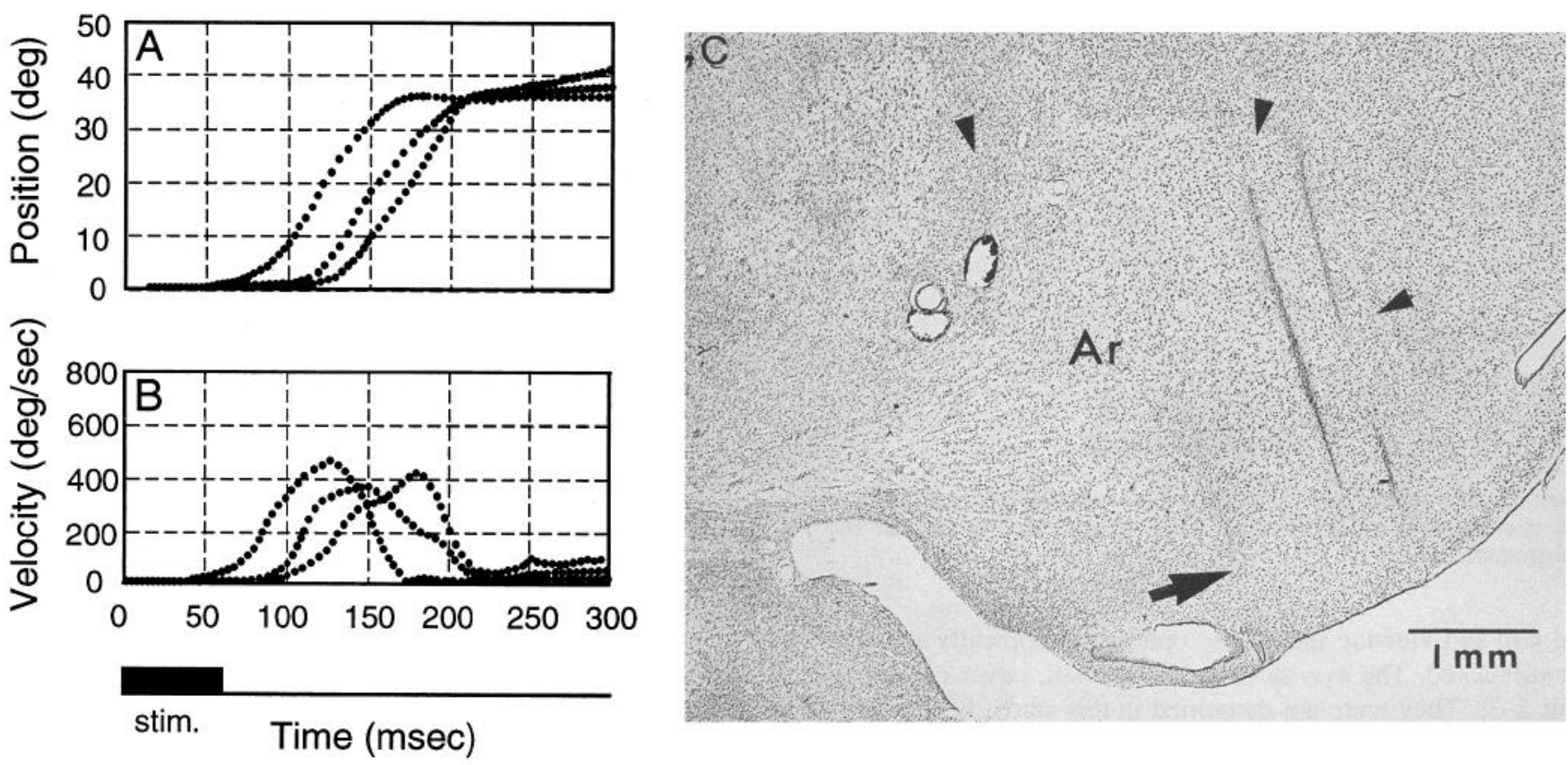

Figure 1. Kinematics of head movements evoked by microstimulation at a single site in the archistriatum (site 18 in Fig. 5). A, Head position in the horizontal plane versus time after onset of stimulation for three trials using identical stimulation parameters. $B$, Head velocity in the horizontal plane versus time after onset of stimulation for the same three trials. Stimulation parameters: current strength, $400 \mu \mathrm{A}$; train duration, $60 \mathrm{msec}$; pulse frequency, $300 \mathrm{~Hz}$. Variability of movement latency was typical for movements elicited from the archistriatum. $C$, Site of stimulation (arrow) in the archistriatum $(A r)$. Nissl-stained transverse section. Arrowheads indicate the anatomical boundary of the archistriatum.

The OT was injected in two owls, the cervical spinal cord in two owls, and the external nucleus of the inferior colliculus (ICX) in one owl.

Pressure injections of tracers were made with the head immobilized using a bolt cemented to the skull and secured to the stereotaxic device. During two of the injections into the archistriatum, the owls were awake so that eye saccades elicited by microstimulation (see Results) could be used to target the injection. All other injections were made while the owls were anesthetized either with halothane and nitrous oxide or with ketamine $(20 \mathrm{mg} / \mathrm{kg})$ and diazepam $(1.0 \mathrm{mg} / \mathrm{kg})$. The two injections of tracer that were made into the archistriatum in anesthetized owls, as well as the injections into the PA, OT, and ICX, were targeted based on unit responses to acoustic stimulation (Brainard and Knudsen, 1993; Cohen and Knudsen, 1994, 1995). Injections into the cervical spinal cord were placed under visual guidance after exposing the spinal cord at the level of the C2 vertebra (Masino and Knudsen, 1992a).

Glass micropipettes, with tip diameters of $15-30 \mu \mathrm{m}$, were partially filled with BDA or fluorescent beads. The pipette was attached either to a $1 \mu \mathrm{l}$ Hamilton syringe or to a Picospritzer II (General Valve Corp.). The pipette was positioned at the desired site and $0.2-0.7 \mu \mathrm{l}$ of tracer was ejected. The pipette remained in place for about $5 \mathrm{~min}$ before being retracted. The brain surface was treated with chloramphenicol, the skull was sealed with dental acrylic, wound margins were infused with lidocaine, and the bird was allowed to recover.

After 5-12 d, the owls were given an overdose of sodium thiopental and were perfused through the heart with $4 \%$ paraformaldehyde in 0.1 $\mathrm{M} \mathrm{PO}_{4}$ buffer and 5\% sucrose. The brains were sunk overnight in $30 \%$ sucrose, and frozen sections were cut in the transverse plane. Sections that were processed for BDA were mounted on glass slides and observed with light- and dark-field optics. Sections containing latex beads were cleared, then coverslipped with nonfluorescing medium (Krystalon) and analyzed with fluorescence microscopy. The locations of labeled cell bodies, axons and terminals were plotted on transverse atlas sections of the brain with the aid of a camera lucida. Nomenclature for cell groups and fiber tracts is based on studies of the pigeon brain (Karten and Hodos, 1967).

\section{Results}

Microstimulation survey of the forebrain

Orienting head movements were evoked by microstimulation in a large region of the ventral forebrain. The movements consisted of smooth reorientations of the head that had natural (i.e., nearly symmetric) velocity time courses (Fig. 1). Histological reconstruction of the stimulation sites that produced these movements revealed that they were located either in the basal ganglia $(n=$ 20 sites) or in or near the anterior $70 \%$ of the archistriatum ( $n$ $=19$ ), a region we refer to as the AGF. The movements elicited from the basal ganglia (paleostriatum augmentatum, PA, or primitivum, PP) tended to be unnaturally slow. In contrast, those elicited from the AGF attained $V_{\max }$ values (see below) equivalent to those of natural head saccades of comparable size (du Lac and Knudsen, 1990).

This report focuses on the orienting movements evoked from the AGF. These movements qualified as "saccades" because of their symmetric velocity profiles and high $V_{\max }$ values (see Materials and Methods). The parametric data reported here are based on the movements evoked from the 19 reconstructed "archistriatal" sites. Of these sites, 14 were located inside the cytoarchitectonic boundaries of the archistriatum (arrowheads in Fig. 1). The other five sites were located in the lateral portion of the intermediate neostriatum (Nil). Although these latter stimulation sites were centered in the Nil, all of them were within $300 \mu \mathrm{m}$ of the dorsal or lateral border of the anterior archistriatum. The movements elicited from these sites exhibited latencies and kinematics that were indistinguishable from those elicited from the 14 archistriatal sites. Moreover, the expected radius of current spread from each of these sites (see Materials and Methods) included the archistriatum. Therefore, the data from these sites are presented together with the data from the archistriatal sites. It is possible, however, that the Nil itself contains a distinct saccade-generating area.

\section{General characteristics of saccades}

Microstimulation in the AGF produced saccadic movements of the head and eyes. Eye saccades were observed by holding the 


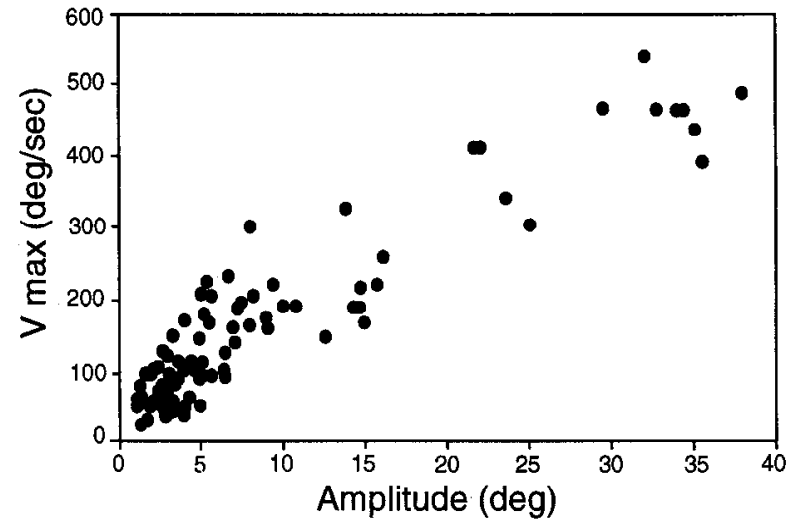

Figure 2. Maximum velocity $\left(V_{\max }\right)$ versus amplitude for each movement elicited from the 19 reconstructed sites located in or near the archistriatum.

head still and viewing the retinae ophthalmoscopically as a site was stimulated. The eye saccades were small, never exceeding about $2-3^{\circ}$. They were not quantified in this study, because eye saccades, independent of head movements, contribute little to changes of gaze in owls (du Lac and Knudsen, 1990).

Evoked head saccades exhibited natural kinematics. However, despite the use of constant stimulation parameters and suprathreshold current levels (usually two times threshold; see Materials and Methods), the latency, amplitude and/or $V_{\max }$ of the saccades varied for some sites. In contrast, the direction of the evoked saccades was consistent at all sites under these conditions.

Across all 19 AGF sites, threshold stimulation currents required to elicit head saccades ranged from 60 to $350 \mu \mathrm{A}$. Minimum saccade latency ranged from 25 to $128 \mathrm{msec}$ (median $=$ $65 \mathrm{msec}$ ); maximum amplitude ranged from $4^{\circ}$ to $38^{\circ}$ (median $=11^{\circ}$ ); and maximum $V_{\max }$ ranged from 81 to $538^{\circ} / \mathrm{sec}$ (median $=283 \% \mathrm{sec}$ ). $V_{\max }$ increased systematically as a function of saccade amplitude for individual movements, and approached $500 \%$ sec for movement amplitudes on the order of $30^{\circ}$ (Fig. 2).

\section{Effect of stimulation parameters}

An effect of stimulation parameters on saccade amplitude was observed qualitatively at all 19 sites in the AGF. Increasing current strength above threshold strength or increasing pulse frequency over the range of $200-400 \mathrm{~Hz}$ tended to increase the amplitude of movement, the amount of increase varying from site to site. Changing these stimulation parameters did not alter appreciably the direction of movement.

We explored quantitatively the effects of stimulation parameters on saccades evoked from three sites. The results were similar for all three sites and a representative example of the results from one site is shown in Figure 3. Mean saccade direction (open circles in Fig. 3) was essentially independent of current strength, pulse frequency or train duration. In contrast, mean saccade amplitude (solid circles in Fig. 3) increased with current strength and with pulse frequency. Mean amplitude was independent of train duration over the range of 30-90 msec. Longer train durations evoked larger movements, but the kinematics of these larger movements were abnormal: the movements consisted of a rapid rotation followed by a continued, slower rotation that lasted for the duration of the stimulation. The velocity profiles of these unnatural movements were highly asymmetric. A similar effect of long duration stimulation on the kinematics
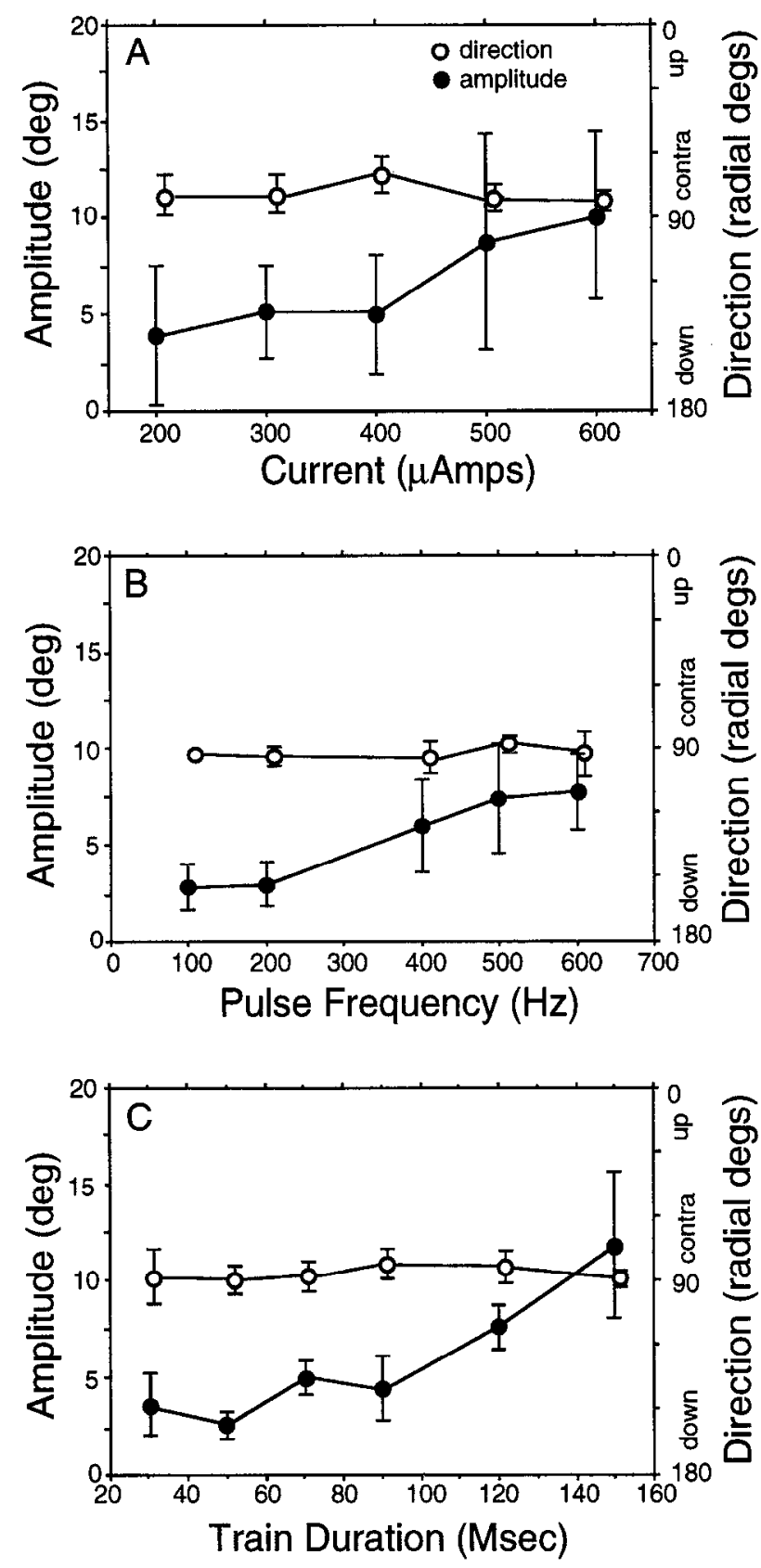

Figure 3. Dependence of movement direction and amplitude on stim ulation parameters. $A-C$, Data from a single stimulation site (site 1 in Fig. 5). The head started from a centered position for all movements. Open symbols represent the mean direction for five or more inovennents; solid symbols represent the mean amplitude for the same movements. Error bars represent standard deviation. A, Current strength versus movement direction and amplitude. Pulse frequency and train duration were held constant at $400 \mathrm{~Hz}$ and $70 \mathrm{msec}$, respectively. The current threshold to elicit consistent movement from this site was $200 \mu \mathrm{A} . B$, Pulse frequency versus movement direction and amplitude. Current strength and train duration were held constant at $400 \mu \mathrm{A}$ and $70 \mathrm{msec}$, respectively. $C$, train duration versus movement direction and amplitude. Current strength and pulse frequency were held constant at 400 $\mu \mathrm{A}$ and $400 \mathrm{~Hz}$, respectively.

of head saccades has been observed in the owl's optic tectum (du Lac and Knudsen, 1990). Long duration stimulation did not evoke "staircase" head saccades similar to the staircase eye saccades that are evoked by stimulating in the FEF or superior colliculus of primates (Robinson, 1972; Bruce, 1990). 

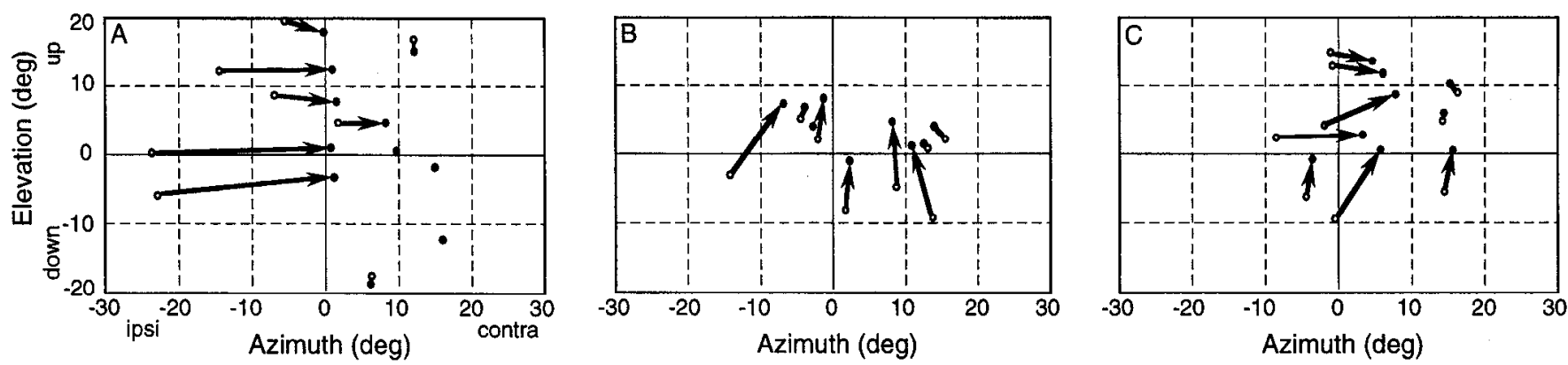

Figure 4. Effect of starting head position on saccades elicited from single sites in the archistriatum. Vectors represent the change in head position between movement onset (open circles) and offset (solid circles). Rotations of less than $3^{\circ}$ were not assigned vectors. Head positions were measured relative to the midsagittal plane of the body (azimuth) and relative to the visual plane when the head was centered on the body (elevation). The data are from site $18(A)$, site $9(B)$, and site $13(C)$, as reconstructed in Figure 5. $A$ and $B$ illustrate horizontal and upward movements, respectively. $C$ illustrates the greatest variation in movement direction with starting head position that was observed at any AGF site.

\section{Effect of starting head position}

Starting head position had little effect on the direction of stimulation-evoked head saccades (Fig. 4); the largest variation in saccade direction with starting head position that was observed is shown in Figure $4 C$.

In contrast, starting head position had a substantial influence on saccade amplitude. At all 19 sites, saccades that tended to center the head on the body (centripetal saccades) were larger than saccades that turned the head away from the centered position (centrifugal saccades). Indeed, for 16 of the 19 sites, there was at least one starting head position from which centrifugal movements could not be elicited (Fig. 4). At these starting head positions, microstimulation caused a sudden increase in neck muscle tonus, but no rotation of the head. At no site were saccadic movements in the opposite direction induced when the head began at positions beyond those from which centrifugal saccades were not induced.

\section{Representation of saccade direction}

The directions of saccades elicited from single sites were not affected systematically by stimulation parameters or by starting head position. Therefore, we searched for evidence of a topographic representation of saccade direction in the AGF.

A wide range of saccade directions was represented in the AGF, based on the average directions elicited from the 19 reconstructed sites (Fig. 5). Contraversive saccades were elicited from 17 sites; the directions ranged from $24^{\circ}$ to $130^{\circ}$. One site produced straight upward movements (site 9, Fig. 5) and the other produced ipsiversive movements (site 14, average direction $-78^{\circ}$; Fig. 5).

There was no apparent correspondence between the location of the site of stimulation in the archistriatum and the movement direction that was produced (Fig. 5). For example, saccades with an upward component could be evoked from sites that were located medially (sites 9 and 14), laterally (sites $4,5,12$ ), dorsally (sites $12,17,19$ ), ventrally (sites 3,9 ), anteriorly (sites 12 , 14), or posteriorly (sites 2,3 ) in the AGF. Horizontal contraversive saccades were elicited from a dorsal posterior region (site 1) as well as from a ventral intermediate region (site 18) in the gaze field. Thus, equivalent movement directions were evoked from different, sometimes widely spaced locations in the AGF.

Although there was no apparent global organization of saccade direction in the archistriatum, there was evidence of local organization, in that neighboring sites in individual owls tended to produce saccades with similar directions (e.g., sites 4 and 5 , sites 6 and 7, and sites 17 and 18; Fig. 5). To investigate this possibility in more detail, saccade direction was measured at sequential $500 \mu \mathrm{m}$ intervals in three electrode penetrations through the AGF in one owl. Stimulation parameters and starting head position were held constant during these penetrations (see Fig. 6 caption), unlike at the other 19 sites, where stimulation parameters and starting head position were adjusted for each site (see Materials and Methods). Marking lesions were not made at these sites. However, marking lesions made in subsequent experiments indicated that the microdrive coordinates for these penetrations corresponded with the central portion of the AGF.

In each of the three penetrations, saccade direction changed continuously with stimulation site over short distances (Fig. 6). In penetrations 1 and 2 , saccades became more downwardly directed as the elcctrode moved ventrally. In contrast, in penetration 3 , saccades became more upwardly directed as the electrode moved ventrally. Thus, the results were consistent with a locally organized representation of saccade direction in the AGF.

\section{Effect of tectal inactivation}

The dependency of head saccades evoked by AGF microstimulation on OT circuitry was tested by reversible inactivation of the OT with lidocaine (see Materials and Methods). The effect of OT inactivation on saccades evoked by $\Lambda$ GF stimulation was tested at four AGF sites in two owls. The data shown in Figure 7 are representative of the results. Within $10 \mathrm{~min}$ of injecting lidocaine into the OT, saccadic movements could no longer be evoked by OT stimulation (Fig. $7 B$ ). Instead, OT stimulation resulted in a slow contraversive rotation of the head. At this time, stimulation of the AGF site, which produced head saccades previously (Fig. $7 \mathrm{C}$ ), continued to evoke head saccades in the same direction (Fig. 7D). However, the amplitude of these saccades was reduced, the latency was increased, and they were preceded by a slight rotation of the head that began at a latency approximately equal to the preinjection saccade latency. Nevertheless, the rapid portion of the head movement satisfied the kinematic criteria for a saccade (see Materials and Methods).

\section{Anatomy}

Anterograde and retrograde tracers were used to identify anatomical connections of the archistriatum that could mediate stimulation-induced saccades. BDA was injected unilaterally into the archistriatum in four owls. In the brainstem, branching axons and terminal labeling were found bilaterally in nuclei known to contribute to saccadic movements in the owl (du Lac and Knud- 
Stimulation Sites
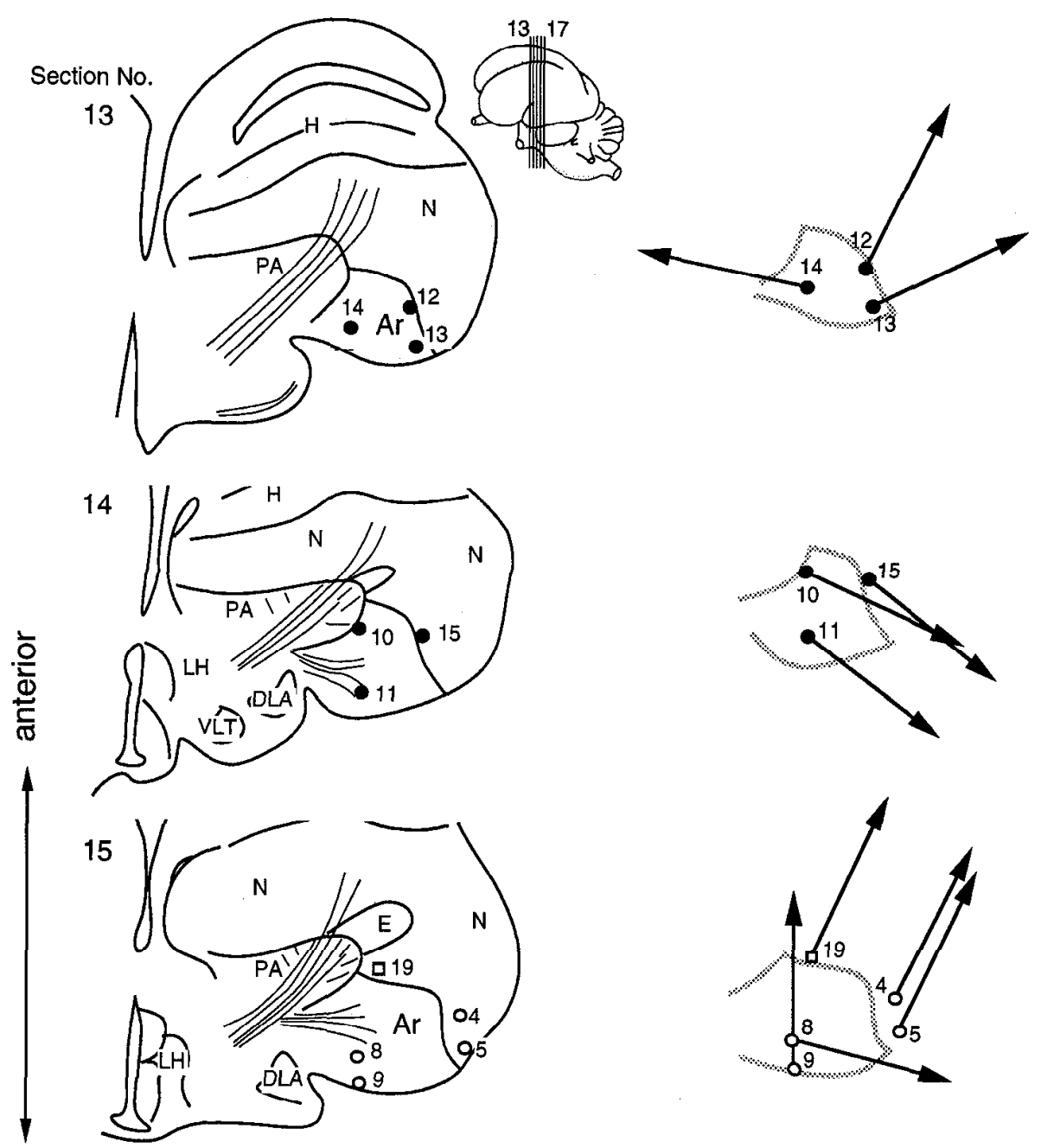

Figure 5. Average saccade direction for each of the 19 stimulation sites located in or near the archistriatum. The sites shown on the left are from three owls; sites represented by the same symbol are from an individual owl. Locations were reconstructed from electrolytic lesions placed at or near each stimulation site, and are plotted on camera lucida drawings of a standard series of transverse Nissl-stained sections, cut as shown in the inset. The interval between the illustrated sections is $540 \mu \mathrm{m}$. The vectors on the right represent the average saccade direction for all movements greater than $2^{\circ}$ elicited from each site. The origin of each vector corresponds with the location of the stimulation site in the archistriatum, the borders of which are indicated by the shaded line. Ar, Archistriatum; DLA, nucleus dorsolateralis anterior thalami; $E$, ectostriatum; $H$, hyperstriatum; $L H$, lateral hypothalamus; $N$, neostriatum; $O T$, optic tectum; $P A$, paleostriatum augmentatum; $P P$, paleostriatum primitivum; $V L T$, nucleus ventrolateralis thalami.

은
16
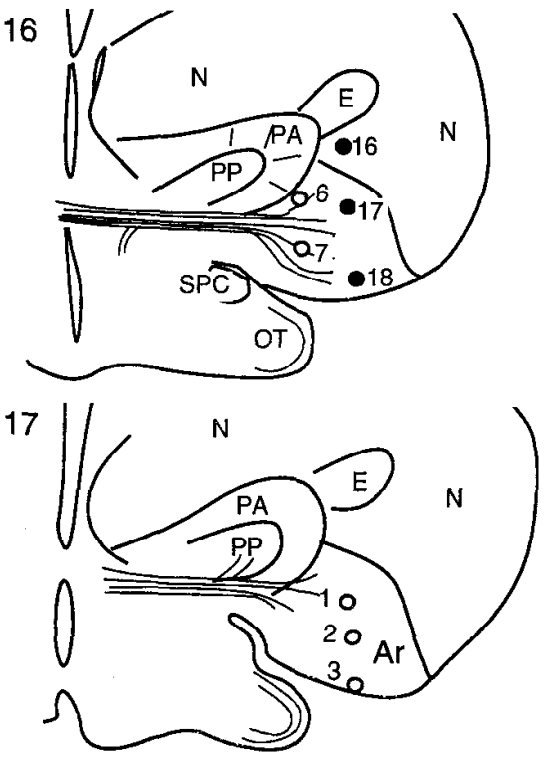

$2 \mathrm{~mm}$
Movement Direction
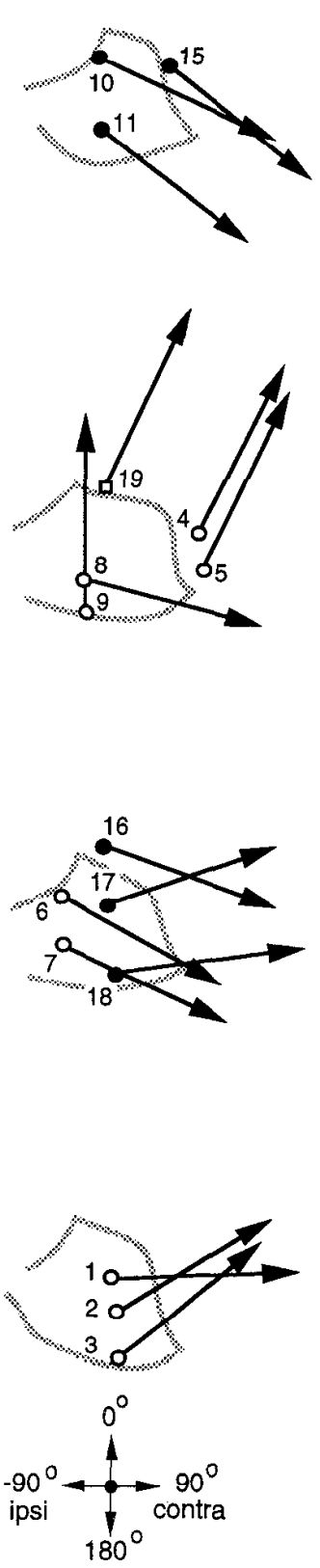


\section{Penetration No.}

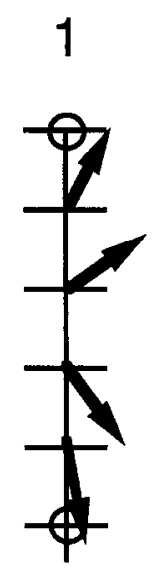

Other brainstem structures that contained anterograde label were the following. Nuclei labeled ipsilaterally were nucleus superficialis parvocellularis (SPC), nucleus semilunaris (SLu), and nucleus isthmi (Is). Nuclei labeled bilaterally were nucleus tegmentipedunculopontinus pars compacta (TPc), pretectal nucleus (PT), and nucleus intercollicularis (IcO). In addition, a tract of fibers was labeled that descended ipsilaterally at least to the level of the caudal medulla.

The forebrain contained anterograde and retrograde BDA labelling from archistriatal injections (Fig. 8). Anterograde terminal labelling was found in the ipsilateral PA of the basal ganglia. Retrogradely filled somata were located ipsilaterally in the lobus parolfactorius in the rostral forebrain (data not shown) and in the intermediate and caudal neostriatum (Fig. $8 A, B$ ). In the intermediate neostriatum, large groups of labeled somata were clustered near the lateral edge of the brain, just lateral and caudal to the archistriatum. In the caudal neostriatum, labeled cells were widely scattered in and around the auditory area, Field L. In addition, labelled axons were observed in the anterior commissure and in the contralateral archistriatum.

In order to verify some of the connections that were indicated by the anterograde labeling from the archistriatum, retrograde tracers were injected into some of the target nuclei. After fluorescent beads were injected into the PA in one owl, a cluster of retrogradely filled somata were found along the ventral edge of the ipsilateral archistriatum (Fig. 10A). Filled cells were also found near the medial edge of the archistriatum, among the fibers of the anterior commissure.

The deep layers of the OT were injected unilaterally with BDA in two owls. In both cases, a cluster of somata were labeled in the ipsilateral medial archistriatum, at the level of the anterior commissure (Fig. 10B). A few labeled somata were also found at approximately the same location on the contralateral side. sen, 1990; Masino and Knudsen, 1992b; Wagner, 1993): interstitial nucleus of Cajal $(\operatorname{lnC})$, nucleus Darkschewitsch (Dk), red nucleus ( $R u$ ), mesencephalic reticular formation (MRF), external nuclcus of the inferior colliculus (ICX), decp layers of the OT, and pontine reticular formation (RP) (Figs. 8, 9). In all of these cell groups, the density of label was much higher on the ipsilateral side than on the contralateral side.
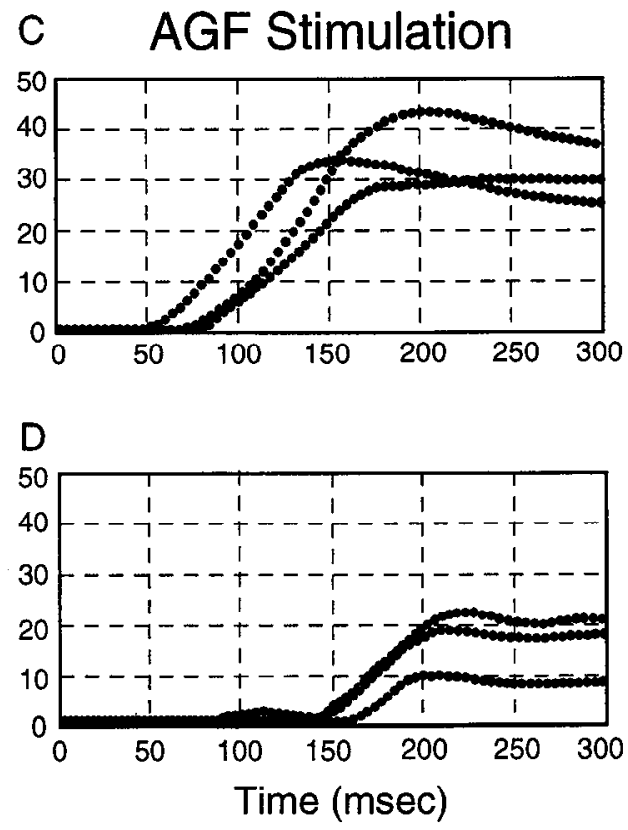

Figure 7. Effect of OT inactivation on head saccades elicited by stimulating the OT or the AGF. Each panel shows the change in head position evoked by stimulating the OT or the AGF three times. The interstimulation interval was 10 sec. The top row $(A$ and $C$ ) shows the head movements elicited before OT inactivation. The bottom row $(B$ and $D)$ shows the movements elicited by stimulating the same sites approximately 10 min after $2 \mu \mathrm{l}$ of a $2 \%$ lidocaine solution was injected into the ipsilateral OT (see Materials and Methods). Tectal stimulation: $120 \mu \mathrm{A}, 40 \mathrm{msec}, 300 \mathrm{~Hz}$. Archistriatal stimulation: $400 \mu \mathrm{A}, 60 \mathrm{msec}, 300 \mathrm{~Hz}$. 

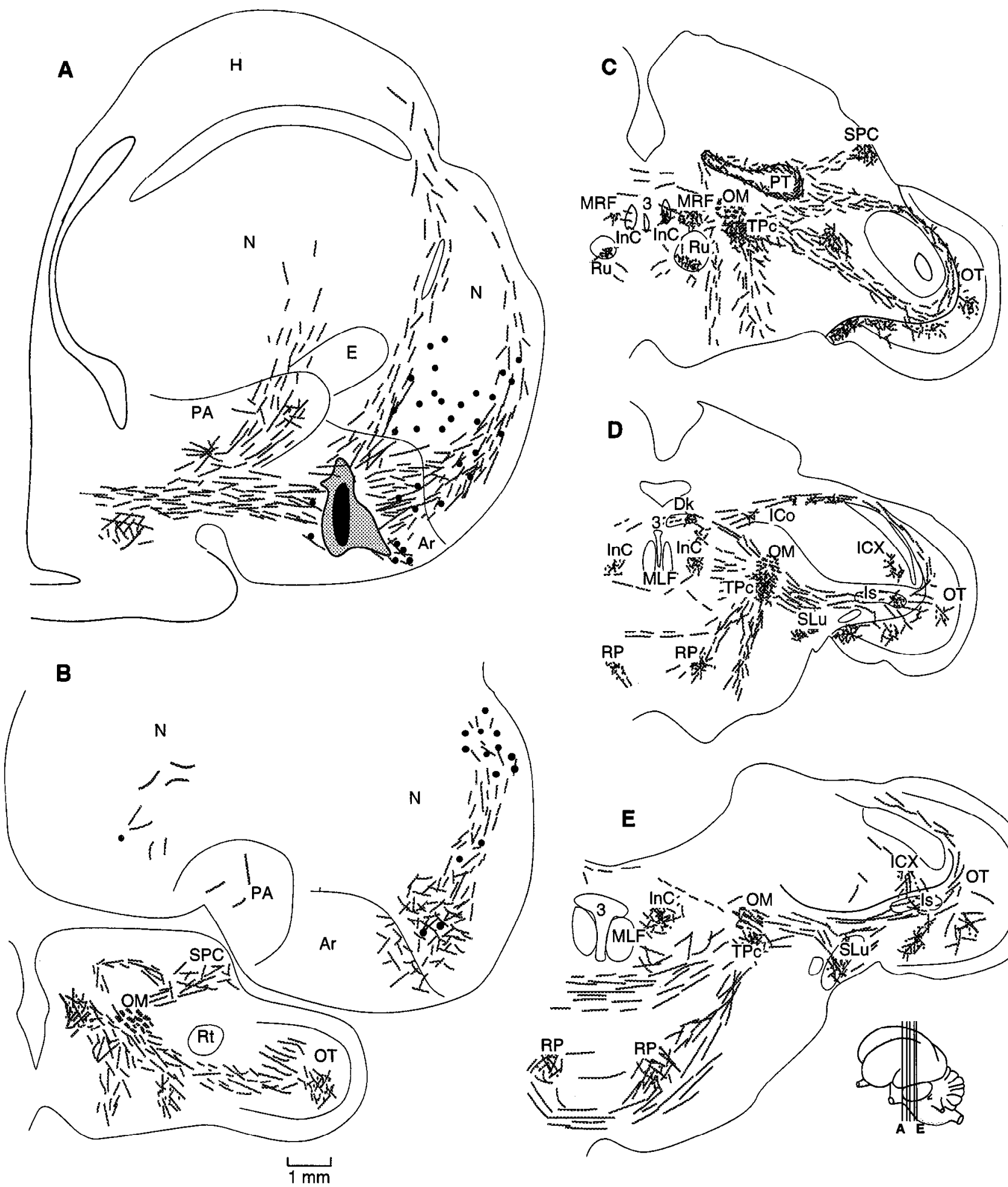

Figure 8. Anterograde and retrograde labelling following a BDA injection into the archistriatum of owl AO. Camera lucida drawings illustrate the injection site $(A)$ and the axons and somata that were labelled as a result of the injection. The planes of section are indicated in the inset at the lower right. The injection site, shown in $A$, contained a region of dense BDA labeling (black area) and a halo of light labeling (shaded area). Labeled axons are represented by shaded lines; labeled somata are represented by large black dots. Abbreviations: 3, oculomotor nucleus; Ar, archistriatum; $D k$, nucleus Darkschewitsch; $H$, hyperstriatum; $I c O$, nucleus intercollicularis; $I C X$, external nucleus of the inferior colliculus; $I n C$, interstitial nucleus of Cajal; Is, nucleus isthmi; $M L F$, medial longitudinal fasciculus; $M R F$, mesencephalic reticular formation; $N$, neostriatum; $O M$, tractus occipitomesencephalicus; $O T$, optic tectum; $P A$, paleostriatum augmentatum; $P T$, nucleus pretectalis; $R P$, pontine reticular formation; $R t$, nucleus rotundus; $R u$, red nucleus; $S L u$, nucleus semilunaris; $S P C$, nucleus superficialis parvocellularis; $T P c$, nucleus tegmentipedunculopontinus pars compacta. 

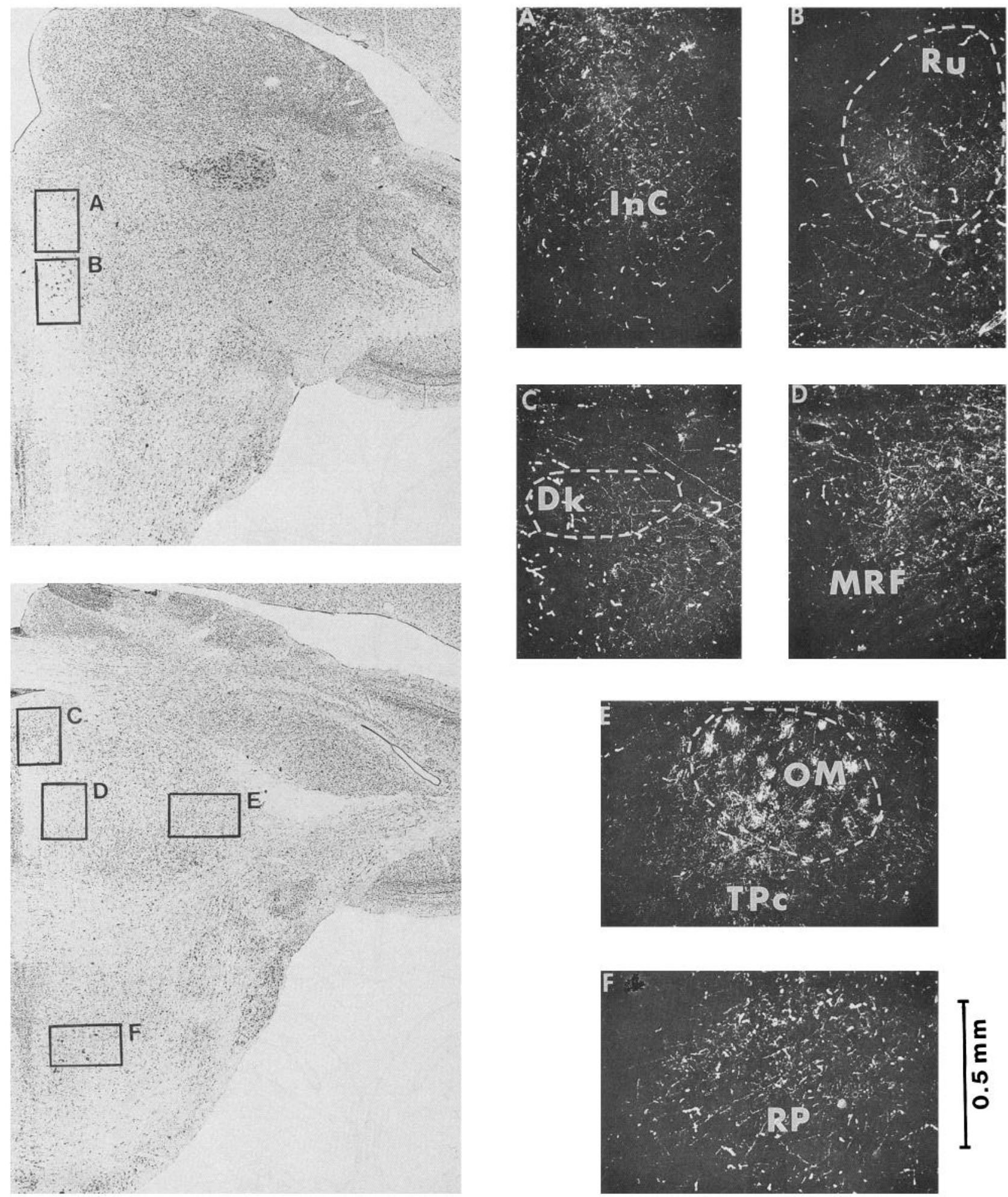

Figure 9. Anterograde labeling in midline brainstem tegmental nuclei resulting from a BDA injection into the archistriatum of owl AO. The site of the injection is shown in Figure 8A. On the left are transverse Nissl-stained sections showing the midline tegmental nuclei at low power. The sections correspond approximately to sections $C$ and $D$ in Figure 8. The boxes, overlaid on these sections, indicate the regions shown at high power in the dark-field photomicrographs on the right. $A-F$, Dark-field photomicrographs of transverse sections showing anterograde BDA labeling in various midline tegmental nuclei. $A$, Interstitial nucleus of Cajal. $B$, Red nucleus. $C$, Nucleus Darkschewitsch. $D$, Mesencephalic reticular formation. $E$, Occipitomesencephalic tract and nucleus tegmentipedunculopontinus pars compacta. $F$, Pontine reticular formation. 
Injection Site
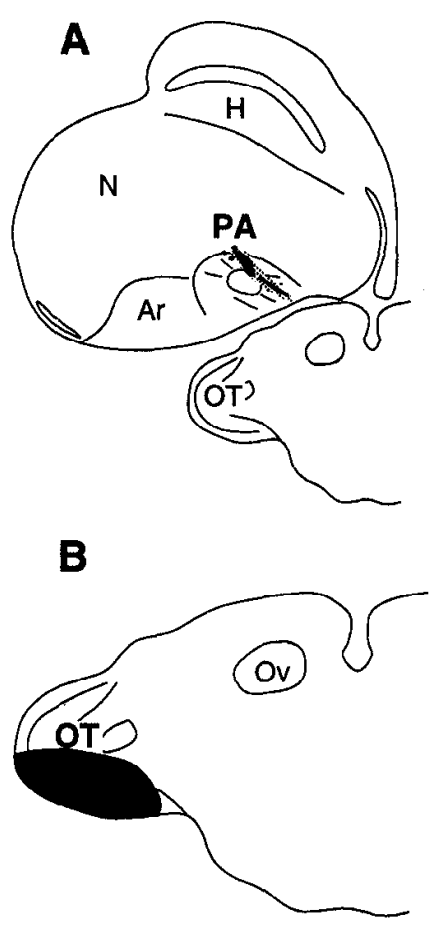

C
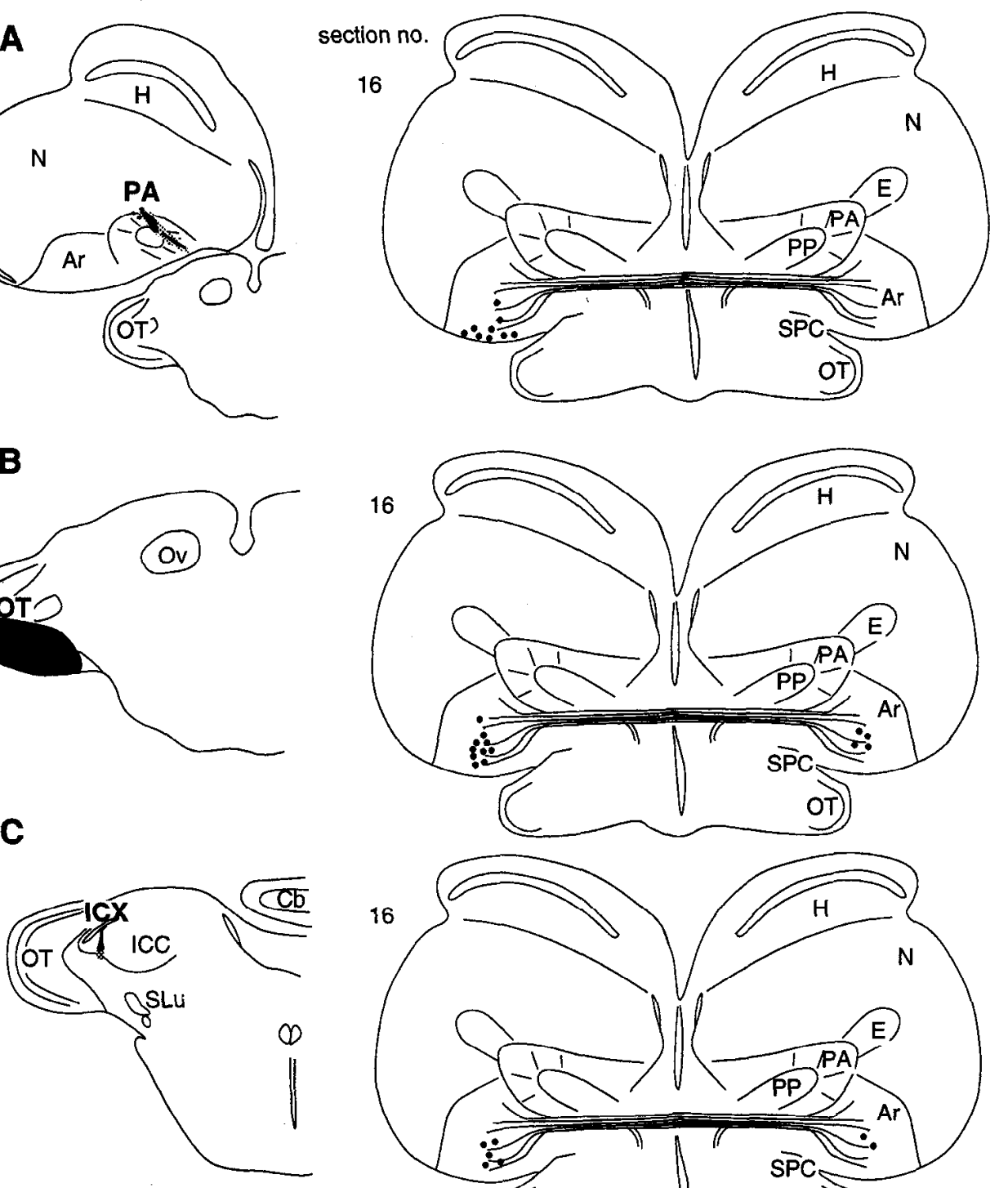

D

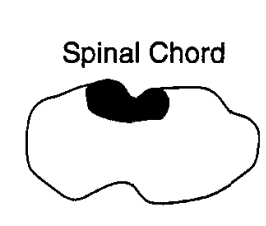

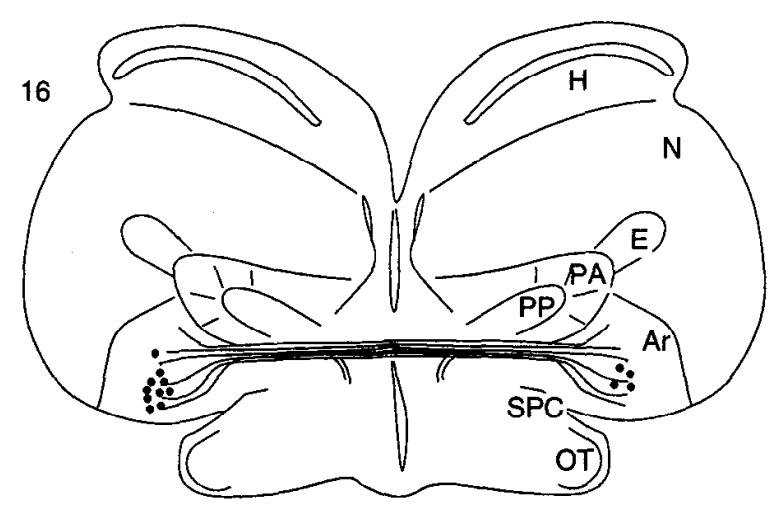

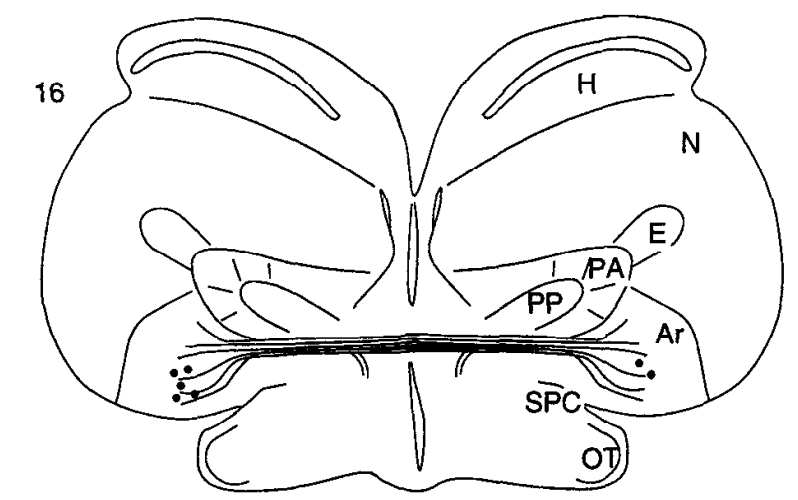

Retrograde Label In Archistriatum

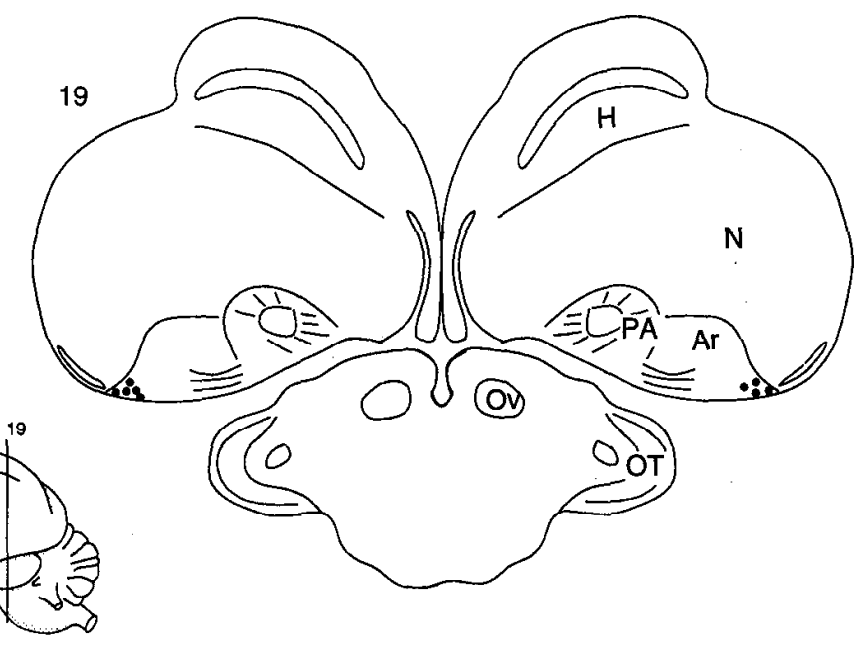


The ICX in one owl was injected unilaterally with fluorescent beads. The injected label spread into the reticular formation just below the ICX (Fig. 10C). Although this region contains fibers to and from the OT, beads are not supposed to be taken up by fibers of passage unless the fibers are severed (Katz et al., 1984). Nevertheless, the pattern of retrograde labelling in the archistriatum was similar to that resulting from the OT injections (Fig. $10 C$ ). The main difference was that fewer somata were labeled which was probably due to the much smaller size of the ICX injection compared to the OT injections.

Finally, to determine whether the tract of fibers that descends from the archistriatum to the level of the medulla reaches the level of the spinal cord, we injected fluorescent beads into the cervical spinal cord in two owls. The injection sites included both sides of the spinal cord (Fig. 10D). Numerous retrogradely filled somata were located bilaterally in the posterior portion of the archistriatum (posterior to the AGF), clustered near the ventrolateral edge on each side.

\section{Discussion}

The physiological and anatomical data presented in this report argue for a role of the archistriatum in the control of gaze in the barn owl. We first discuss the saccadic gaze shifts that are produced by microstimulating in the AGF. Then we review the anatomical pathways by which the AGF might influence gaze direction and summarize the results indicating that the AGF and the OT have independent access to premotor circuitry for generating head and eye saccades. Finally, we compare the physiological and anatomical findings of this study with those of prior studies in primates and argue that the barn owl AGF may be functionally analogous to the primate FEF.

\section{Definition of the $A G F$}

We have employed the microstimulation technique, used traditionally to define "eye fields" in monkeys (Bruce, 1990), to identify a gaze field, the AGF, in the anterior portion of the archistriatum of the barn owl. In owls, eye movements are highly restricted (less than $3^{\circ}$ ), and this species changes its direction of gaze primarily by turning the head. Nevertheless, saccadic head and eye movements have the same goal: they reorient the animal's gaze in a new direction. Microstimulation, when applied at most sites in the AGF, causes a rapid shift of gaze by producing contraversive head and eye movements with kinematic properties similar to those of natural saccades (du Lac and Knudscn, 1990).

The levels of current required to elicit head saccades from the AGF $(60-350 \mu \mathrm{A})$ are equivalent to those required to elicit head saccades from the optic tectum (du Lac and Knudsen, 1990) and eye saccades from the superficial and intermediate layers of the superior colliculus in primates and cats (Robinson, 1972; Guitton et al., 1980). Sites with lower current thresholds $(<50 \mu \mathrm{A})$, such as are found in the FEF and in the deep layers of the superior colliculus in primates, were not encountered. The discrepancy in current thresholds for eliciting owl head saccades and primate eye saccades we think is not related to technique, but rather to differences in the size of the neuronal populations that must be recruited to evoke head versus eye movements, differences in cyto- and myeloarchitecture in the respective structures, and/or differences in the intrinsic or projectional patterns of connectivity between these structures.

There is inherent uncertainty in identifying the population of neurons that is activated by electrical microstimulation. The distance over which current is effective in activating neurons varies with changes in the local impedance of the tissue, and fibers passing through the tissue that originate from cell bodies located in distant structures may be activated. Because of this uncertainty, we cannot exclude the possibility that some of the movements evoked by stimulating in the AGF resulted from the activation of neurons located outside of the archistriatum. However, anatomical data presented in this and in other studies (Zeier and Karten, 1971; Nottebohm et al., 1976) indicate that the archistriatum is the source of motor-related output from the avian forebrain. Moreover, microstimulation applied at sites more than a few hundred micrometers from the borders of the archistriatum did not evoke saccades. In addition, the abrupt elimination of movements (Fig. 6) and the abrupt changes in saccade direction (e.g., sites 8 and 9 in Fig. 5) that could result from small changes in electrode position, even within the AGF itself, indicate that the radius of effective current spread was relatively small in these experiments.

A more likely consequence of the spatial imprecision inherent to microstimulation is that the extent of the AGF was overestimated. We were able to elicit head saccades from sites throughout most of the anterior $70 \%$ of the archistriatum. Although gaze control is an important behavior in barn owls, it is only one of many that must be mediated by the archistriatum (Zeier, 1971). It is likely, therefore, that when the AGF is studied with more sophisticated techniques, its extent in the archistriatum will be further restricted.

\section{Functional organization in the AGF}

Saccade direction, but not amplitude, appears to be represented as a place code in the AGF. Altering either the parameters of stimulation or the starting head position often changed the amplitude of the saccades that were evoked from a single site (Figs. $3,4)$. In contrast, these parameters had little effect on the direction of the evoked saccades. Saccade direction did change, however, with the site of stimulation (Figs. 5, 6). In this sense, saccade direction was place-coded in the AGF.

Despitc the place code for direction, there was no evidence for a single, continuous map of saccade direction in the AGF. Instead, the same direction of movement could be elicited from multiple, widely spaced sites. Moreover, there were occasional abrupt changes in the movement directions that were evoked from neighboring sites (e.g., sites 8 and 9 in Fig. 5). The same microstimulation technique has been used successfully in the past to reveal a continuous map of saccade direction in the barn owl OT (du Lac and Knudsen, 1990). Thus, were an equivalent map of saccade direction to exist in the AGF, it should have been revealed by this technique.

$\leftarrow$

Figure 10. Retrograde labeling in the archistriatum following injections into various target nuclei. Camcra lucida drawings of injection sites are shown on the left. The locations of somata that were labeled as a result of each injection are indicated by large dots in transverse sections shown on the right. The thin horizontal lines in $A-C$ represent the anterior commissure. $A$, Fluorescent bead injection into the PA. $B$, BDA injection into the OT. $C$, Fluorescent bead injection into the ICX. $D$, Fluorescent bead injection into the spinal cord. Abbreviations as in Figure 8 . $C b$, cerebellum; $E$, ectostriatum; $H$, hyperstriatum; $N$, neostriatum; $O v$, nucleus ovoidalis. 
The results suggest, instead, that saccade direction is organized only on a local scale in the AGF. The direction of saccades tended to change systematically with stimulation site, at least across small distances (Fig. 6). However, the saccade directions that were evoked from sites in neighboring penetrations could not be predicted. Such a local organization is reminiscent of the representation of saccade direction in the primate FEF (Bruce et al., 1985) and of auditory space in the barn owl archistriatum (see following companion article, Cohen and Knudsen, 1995). This organization contrasts with the single, continuous maps of saccade direction and auditory space in the owl optic tectum (Knudsen, 1982; du Lac and Knudsen, 1990) and in the primate superior colliculus (Robinson, 1972; Jay and Sparks, 1987). Thus, both in owls and in primates the global functional organization of spatial information is fundamentally different between closely related structures in the forebrain and midbrain.

\section{Parallel pathways for gaze control}

The archistriatum communicates anatomically with many regions of the brain (Vicario, 1991; Wild et al., 1993), consistent with its role as a sensorimotor processor and as the source of motor-related output from the forebrain (Zeier and Karten, 1971). Connections reported here, that have not been reported previously, are those from the archistriatum to the cervical spinal cord and to midline brainstem tegmental nuclei: $\mathrm{Dk}, \mathrm{InC}, \mathrm{Ru}$, MRF, and RP. The midline brainstem nuclei are thought to contain neural circuitry for generating gaze saccades in barn owls (Masino and Knudsen, 1992b). Neurons in these nuclei project anatomically to the cervical spinal cord (Masino and Knudsen, 1992a), where motoneurons reside that control head position. Electrical activation of any of these nuclei produces short latency (18-19 msec) head saccades. Microstimulation of the $\mathrm{InC}$, $\mathrm{Ru}$ or MRF evokes either upward, downward, leftward, or rightward saccades depending on the site of stimulation (Masino and Knudsen, 1992b). By activating these nuclei in appropriate combinations (Masino and Knudsen, 1990), the AGF could produce gaze saccades in any direction.

The AGF could also produce gaze saccades by a parallel pathway that passes through the OT. The archistriatum projects to the deep layers of the OT both directly and indirectly via the basal ganglia, the TPc (analog of the mammalian substantia nigra pars compacta; Reiner and Carraway, 1987), and the ICX (Knudsen and Knudsen, 1983). The OT, in turn, projects bilaterally to the same midline tegmental nuclei (the $\mathrm{Dk}, \mathrm{InC}, \mathrm{Ru}$, MRF, and RP) as does the archistriatum (Masino and Knudsen, 1992a). Thus, activity in the AGF could produce head and eye saccades either by activating the brainstem tegmental circuitry directly or by activating the OT which, in turn, would activate this circuitry.

The effects of inactivating the OT on saccades evoked by AGF stimulation indicate that the AGF normally engages tectal circuitry when mediating saccadic changes of gaze. OT inactivation decreased the amplitude and increased the latency of saccades evoked from the AGF (Fig. 7). However, it did not eliminate these saccades. The saccades that could still be produced by AGF stimulation following OT inactivation, as well as saccades made by behaving owls following OT inactivation (Knudsen et al., 1993), can be accounted for by the direct activation of tegmental saccade-generating circuitry by the AGF.

Anatomical variation across species

The relative strengths of specific archistriatal connections vary widely across species (Dubbeldam, 1993). In male songbirds, for example, the portion of the archistriatum that is involved in song production (the nucleus robustus archistriatalis) is hypertrophied and cytoarchitectonically distinct (Nottebohm and Arnold, 1976). Projections of this nucleus onto several brainstem nuclei involved in sound production have been observed in songbirds (Nottebohm et al., 1976; Brauth and McHale, 1988; Vicario, 1991) but not in pigeons (Wild et al., 1993). In barn owls, gaze control is highly developed (Knudsen et al., 1979), and the connections that contribute to gaze control appear much stronger than, if not qualitatively different from, analogous connections in pigeons and song birds (Nottebohm et al., 1976; Brauth and McHale, 1988; Vicario, 1991; Wild et al., 1993). Thus, the archistriatum exhibits species-specific anatomical differentiation that varies with the behavioral capacities of the species.

\section{Comparison with the mammalian FEF}

The results of various studies on the contribution of the FEF to gaze control in primates are strikingly similar to the functional and anatomical findings reported here for the barn owl AGF. The only notable exception is that saccade amplitude is mapped in the FEF (Bruce et al., 1985), whereas we found no clear evidence of a map of saccade amplitude in the AGF. Otherwise, in the following respects the FEF and AGF are similar. First, electrical microstimulation elicits primarily contraversive saccades from the FEF (Robinson and Fuchs, 1969) and from the AGF (Fig. 5) Second, saccade direction is place-coded and equivalent directions are represented at multiple, widely spaced sites in both the FEF (Bruce et al., 1985) and the AGF (Fig. 5); in the FEF, this representation resembles a repeating, columnar organization. Third, for single stimulation sites, saccade amplitude varies with starting position, with centripetal saccades being significantly larger than centrifugal saccades (FEF, Russo and Bruce, 1993; AGF, Fig. 4). Fourth, the FEF projects in parallel to the deep layers of the OT, to saccade-generating circuitry in the midline brainstem tegmentum, and to the basal ganglia (Schnyder et al., 1985; Stanton et al., 1988a,b) as does the AGF (Figs. 8, 9). Finally, lesioning the OT does not eliminate saccades elicited by FEF stimulation (Schiller, 1977) or AGF stimulation, but it does decrease the size and increase the latency of saccades (FEF, Schiller et al., 1987; AGF, Fig. 7D).

The similarities in the circuitry for controlling gaze in species as distantly related as primates and barn owls suggest that this organization is well adapted for carrying out the respective roles of the forebrain and midbrain in gaze control. It has been hypothesized that, in primates, the forebrain contributes critically to intentional changes of gaze that require access to memory or that require computations to account for changes in gaze direction that intervene between stimulus detection and the decision to look at the stimulus source (as in the double-step saccade task; Deng et al., 1986; Goldberg and Segraves, 1989; Bruce, 1990). We propose that the forebrain may contribute in a similar manner to gaze control in the barn owl.

\section{References}

Brainard MS, Knudsen EI (1993) Experience-dependent plasticity in the inferior colliculus: a site for visual calibration of the neural representation of auditory space in the barn owl. J Neurosci 13:45894608.

Brauth SE, McHale CM (1988) Auditory pathways in the budgerigar. II. Intratelencephalic pathways. Brain Behav Evol 32:193-207.

Bruce CJ (1990) Integration of sensory and motor signals in primate frontal eye fields. In: From signal and sense: local and global order 
in perceptual maps (Edelman GM, Gall WE, Cowan WM, eds), pp 261-314. New York: Wiley.

Bruce CJ, Goidberg ME (1985) Primate frontal eye fields. I. Single neurons discharging before saccades. J Neurophysiol 53:603-635.

Cohen YE, Knudsen El (1994) Auditory tuning for spatial cues in the barn owl basal ganglia. J Neurophysiol 72:285-298.

Cohen YE, Knudsen EI (1995) Binaural tuning of auditory units in the forebrain archistriatal gaze fields of the barn owl: local organization but no space map. J Neurosci 15:5152-5168.

Deng S-Y, Goldberg ME, Segraves MA, Ungerleider LG, Mishkin M (1986) The effect of unilateral ablation of the frontal eye fields on saccadic performance in the monkey. In: Adaptive processes in the visual and oculomotor systems (Keller E, Zee DS, eds), pp 201-208. Oxford: Pergamon.

Dubbeldam JL (1993) Brain organization and behavior: a discussion of neuronal systems in birds. Acta Biotheor 41:469-479.

du Lac S, Knudsen EI (1990) Neural maps of head movement vector and speed in the optic tectum of the barn owl. J Neurophysiol 63: 131-149.

Fukushima K (1987) The interstitial nucleus of Cajal and its role in the control of movements of the head and eyes. Prog Neurobiol 29: 107-192.

Goldberg ME, Segraves MA (1989) The visual and frontal cortices. In: Reviews of oculomotor research, Vol 3, The neurobiology of saccadic eye movements (Wurtz RH, Goldberg ME, eds), pp 283-313. Amsterdam: Elsevier.

Grobstein P (1988) Between the retinotectal projection and directed movement: topography of a sensorimotor interface. Brain Behav Evol 31:34-48.

Guitton D, Crommelinck M, Roucoux A (1980) Stimulation of the superior colliculus in the alert cat. Exp Brain Res 39:63-73.

Henn V, Hepp K, Buttner-Ennever JA (1982) The primate oculomotor system. II. Premotor system. Hum Neurobiol 1:87-96.

Jay MF, Sparks DL (1987) Sensorimotor integration in the primate superior colliculus. II. Coordinates of auditory signals. J Neurophysiol 57:35-55.

Karten HJ, Hodos W (1967) A stereotaxic atlas of the brain of pigeon (Columbia livia). Baltimore: Johns Hopkins UP.

Katz LC, Burkhalter A, Dreyer WD (1984) Fluorescent latex microspheres as a retrograde neuronal marker for in vivo and in vitro studies of visual cortex. Nature 310:-500.

Knudsen EI (1982) Auditory and visual maps of space in the optic tectum of the owl. J Neurosci 2:1177-1194.

Knudsen EI (1989) Fused binocular vision is required for development of proper eye alignment in barn owls. Vis Neurosci 2:35-40.

Knudsen EI, Knudsen PF (1983) Space-mapped auditory projections from the inferior colliculus to the optic tectum in the barn owl (Tyto alba). J Comp Neurol 218:187-196.

Knudsen EI, Blasdel GG, Konishi M (1979) Sound localization by the barn owl measured with the search coil technique. J Comp Physiol 133:1-11.

Knudsen EI, Knudsen PF, Masino T (1993) Parallel pathways mediating both sound localization and gaze control in the forebrain and midbrain of the barn owl. J Neurosci 13:2837-2852.

Masino T, Knudsen EI (1990) Horizontal and vertical components of head movement are controlled by distinct neural circuits in the barn owl. Nature 345:434-437.

Masino T, Knudsen EI (1992a) Anatomical pathways from the optic tectum to the spinal cord subserving orienting movements in the barn owl. Exp Brain Res 92:194-208.

Masino T, Knudsen EI (1992b) Orienting head movements resulting from electrical microstimulation of the brainstem tegmentum in the barn owl. J Neurosci 13:351-370.
McCasland JS (1987) Neuronal control of bird song production. J Neurosci 7:23-39.

Mcllwain JT (1986) Effects of eye position on saccades evoked electrically from superior colliculus of alert cats. J Neurophysiol 55:97112.

Nottebohm F, Arnold AP (1976) Sexual dimorphism in vocal control areas of the songbird brain. Science 194:211-213.

Nottebohm F, Stokes TM, Leonard CM (1976) Central control of song in the canary, Serinus canarius. J Comp Neurol 165:457-486.

Ranck JB (1980) Extracellular stimulation. In: Electrical stimulation research techniques (Patterson $M$, Kesner R, eds), pp 1-36. New York: Academic.

Reiner A, Carraway RE (1987) Immunohistochemical and biochemical studies on lys $^{8}$-asn" $n^{1}$-neurotensin ${ }^{8-13}$ (LANT6)-related peptides in the basal ganglia of pigeons, turtles, and hamsters. J Comp Neurol 257: 453-476.

Robinson D (1972) Eye movements evoked by collicular stimulation in the alert monkey. Vision Res 12:1795-1808.

Robinson DA, Fuchs AF (1969) Eye movements evoked by stimulation of frontal eye fields. J Neurophysiol 32:637-648.

Russo GS, Bruce CJ (1993) Effect of eye position within the orbit on electrically elicited saccadic eye movements: a comparison of the macaque monkey's frontal and supplementary eye fields. J Neurophysiol 69:800-818.

Schiller PH (1977) The effect of superior colliculus ablation on saccades elicited by cortical stimulation. Brain Res 122:154-156.

Schiller PH, True SD, Conway JL (1980) Deficits in eye movements following frontal eye-field and superior colliculus ablations. J Neurophysiol 44:1175-1189.

Schiller PH, Sandell JH, Maunsell JHK (1987) The effect of frontal eye field and superior colliculus lesions on saccadic latencies in the rhesus monkey. J Neurophysiol 57:1033-1048.

Schnyder H, Reisine H, Hepp K, Henn V (1985) Frontal eye field projection to the paramedian pontine reticular formation traced with wheat germ agglutinin in the monkey. Brain Res 329:151-160.

Segraves MA, Goldberg ME (1987) Functional properties of corticotectal neurons in the monkey's frontal eye field. J Neurophysiol 58: $1387-1419$.

Stanton GB, Goldberg ME, Bruce CJ (1988a) Frontal eye field efferents in the macaque monkey. I. Subcortical pathways and topography of striatal and thalamic terminal fields. J Comp Neurol 271:473-492.

Stanton GB, Goldberg ME, Bruce CJ (1988b) Frontal eye field efferents in the macaque monkey. II. Topography of terminal fields in midbrain and pons. J Comp Neurol 271:493-506.

Stein BE, Meredith MA (1993) The merging of the senses. Cambridge, MA: MIT Press.

Vicario DS (1991) Organization of the zebra finch song control system. II. Functional organization of outputs from nucleus robustus archistriatalis. J Comp Neurol 309:489-494.

Wagner H (1993) Sound-localization deficits induced by lesions in the barn owl's auditory space map. J Neurosci 13:371-386.

Westheimer G (1973) Saccadic eye movements. In: The oculomotor system and brain functions (Zikmund V, ed), pp 57-77. Bratislava: Slovak Academy of Sciences.

Wild JM, Karten HJ, Frost BJ (1993) Connections of the auditory forebrain in the pigeon (Columba livia). J Comp Neurol 337:32-62.

Wurtz RH, Goldberg ME (1972) Activity of superior colliculus in behaving monkey. III. Cells discharging before eye movements. J Neurophysiol 35:575-586.

Zeier H (1971) Archistriatal lesions and response inhibition in the pigeon. Brain Res 31:327-339.

Zeier H, Karten HJ (1971) The archistriatum of the pigeon: organization of afferent and efferent connections. Brain Res 31:313-326. 